\title{
To the Legal Support of the Solution of Bioethical Problems in the Republic of Azerbaijan
}

\author{
Nigar Huseyn Galandarli ${ }^{1}$ \\ ${ }^{1}$ Institute of Human Rights, National Academy of Sciences of the Republic of Azerbaijan, Azerbaijan \\ Correspondence: Nigar Huseyn Galandarli, Institute of Human Rights, National Academy of Sciences of the \\ Republic of Azerbaijan, Azerbaijan. E-mail: ngalandarli@mail.ru
}

Received: May 19, 2013 Accepted: June 12, 2013 Online Published: August 30, 2013

doi:10.5539/ass.v9n11p57

URL: http://dx.doi.org/10.5539/ass.v9n11p57

\begin{abstract}
This article focuses on the ethical problems connected with human rights which practically affect all sides of vital activity of society. Along with social, biological and medical aspects, a legal one is of no less importance and that is why its legal prerequisite became a main factor in the development of modern bioethics. The model of legal support of bioethical problems consists of the formation of institutional environment, legislative framework, well-thought-out education policy and creation of necessary social and ethical structures. All these aspects have been analyzed.
\end{abstract}

Keywords: human rights, bioethics, euthanasia, human beings, human dignity

\section{Introduction}

The social security of a human being in all the areas of its activities and the degree of the realization of rights to the safety of life, health and dignity are modern criteria of the prosperity of any state. Ensuring of these rights becomes more and more topical in the progressive development of sciences, technologies and techniques. One of the most important moral factors of policy pursued by the states is the provision of maximum attainable level of quality of life. Today the scopes of bioethics as science are not limited with moral issues exclusively in the field of medicine and healthcare. Ethical observations relating to human rights have an effect upon all social problems and that is why its legal message becomes a main factor in the development of modern bioethics. About half a century, the scientists, researchers and community believe bioethics to be a young science. However, it has long ago overstepped the thresholds of the purposes declared upon its establishment. The word bioethics assumed a wider meaning and is a symbiosis of innumerable factors from life (bios) with values and obligations (ethos) accepted in society.

\section{The Evolution of Bioethics as Science}

The field of the study in bioethics is as wider as life. The present thesis considers not only the issues of deontology, i.e. relations of medical workers with patients. In all the spheres of human life activity there are cases that require the adoption of adequate solutions in terms of universal human values and morals. This a priori fact attaches the status of "suspension" science to bioethics with respect to all human sciences. All the living human beings, all future generations, all living organisms and environment make a range of activities of various bioethical researches. "Bioethics is a noun in plural. And the plurality of moral positions is real. It is real in fact and in principle" wrote Tristan Engelhardt Jr., a well-known American philosopher in the foreword to its fundamental work "Foundation on Bioethics" (Tishenko, 2009). The Russian scientist B. Yudin who studies the problems of bioethics from the beginning of its formation as science states that "bioethics should be understood not only as a field of knowledge, but as a forming social institute of modern society" (Yudin, 1994). Until recently the prevalence of interests of the government and science over rights, freedoms and interests of a single individual dominated in the society. Today the situation is changing. The example of the recognition of the priority of personal rights and freedoms in the field of healthcare is Convention on Protection of Human Rights and Dignity of the Human Being With Regard to the Application of Biology and Medicine (Council of Europe, 1997). The Article 2 - Human Priority of the Convention says: "Interests and benefit of a single individual prevails over the interests of the society or science. (Mustafayeva, 2009)

The evidences of the recognition of the priority of interests of an individual in civil countries are all adopted and 
developing international documents. The following postulates are inalterable at any stage of development of bioethics as a science:

1) Humanistic values and scientific and technological progress should be integrated.

2) Humanistic aims have a priority with respect to exploratory ones.

3) There should be control and management of scientific researches, not excluding their prohibition.

4) The development and realization of rules of conduct for any works, executions, researches and scientific activities with the mandatory consideration of personal rights including legal standards ensuring them.

\section{The Conceptualization of Bioethics}

The situation in the modern globalizing world is characterized by much more great number of challenges and threats than ever before. The radically changing attitude of a human being towards the world and himself causes serious conflicts and problems the solution of which affects a proper existence of a human being as a biological species. The harmony of nature and culture is violated substantially and some additional efforts required restore the balance. That's why the problem of conceptualization of bioethics as an integral part of culture today is a topical one to the limit. Different moral principles and different values are taken into account in making decisions on every certain case which is disputable in an ethical context. As a rule, to choose a right decision is difficult enough. The objective life circumstances and morals are often in a state of potential conflict. It is evident that the problem of observing humanistic and moral values gets more sophisticated manifold in more democratic historical periods as the modern stage of mankind development is. In the prior state regime when the decisions were made by one person and the rest had to obey, the occurrence of ethical conflicts was minimal. There even did a legal rationale exist in a form of legal sets of rules. Modern societies with characteristic respect to human rights and freedoms, cultural pluralism and moral diversity are conflictogenic in terms of clash of interests, necessity of implementation of one or another action and its impossibility for ethical reasons. In 1975 the UN General Assembly adopted the Declaration on the Use of Scientific and Technological Progress in the Interests of Peace and for the Benefit of Mankind. It expresses concern about the creation of "social problems threatening human rights and fundamental freedoms" as a result of scientific and technological achievements (Mustafayeva, 2009). The Declaration obliges the states joined it "to take all the respective measures in order to prevent the use of science and technology achievements, particularly by public authorities for the restriction of or interference in the implementation of human rights and fundamental freedoms proclaimed in the Universal Declaration of Human Rights (1948), International Conventions on Political, Social and Cultural Human Rights (1966) and other appropriate international documents" (www.un/org/documents/decl_conv/conventions). And further, "all the states must take necessary measures including legislative ones in order to ensure that the use of science and technology achievements facilitates the fullest implementation of human rights without any discrimination on the basis of race, sex, language or religious beliefs". In addition, it should be noted that the ethical principles declared in the Resolution of the UN General Assembly in 1981 concerning the role of professional employees in the areas connected with life and health of a human being act "without any deviations from them and on no grounds including state of emergency" (Mustafayeva, 2009).

Edmund D. Pellegrino, a well-known scientist in bioethics, Professor of Georgetown University, a member of Research Center of Kennedy Institute of Ethics, in his special monograph dedicated to the analysis of bioethics in USA states that interaction of four basic forces such as scientific progress, moral pluralism, democratization and economic factors led to the emergence of bioethics. Disclosing the content of each of these forces he points to "the demonstration growth of knowledge and technologies of natural sciences". "Now the physicians have opportunities they couldn't even imagine before. This includes "reproductive techniques, genic technologies, domination over infectious diseases, transplantation of organs and the change of behavior, prenatal surgery, etc. All the above-mentioned carry an unprecedented challenge to traditional moral values" (Siluyanova, 2001), (Hang-Martin, 1988).

\section{The Problematic Issues of Bioethics}

Let's take euthanasia as an example of one of the most important problems of bioethics. The modern society proved to be split to this phenomenon affecting the basic right of a human being - his right to life. The euthanasists think that a human being also has the right to death. In a legal sense the consensus in this problem is very difficult. The well-known Azerbaijani expert in euthanasia, President of Heydar Aliyev Fund, Goodwill Ambassador UNESCO and ISESCO Mrs. Mehriban Aliyeva thinks: "Deprivation of human life even if for humanistic reasons is difficult to combine with conceptions on human dignity", - and further - "the modern society proved to be at the crossroads. Under the present conditions one should follow the path of elimination of 
any factors inciting people to think about euthanasia" (Aliyeva, 2005). The American scientist J. Gay-Williams sticks to the same position and notes in his inquiries: "Euthanasia is an act of gross violation of natural will to survive. If euthanasia is to be permitted we shall die needlessly; death is an end and the possibility of error is too great to approve euthanasia" (Gay-Williams, 1989) Back in ancient times the scholars spoke in favor of "life": "A true courage is not to call death but to fight with it" - so did Lusius Anney Seneca think (Seneca, 1977). In his "letters" that are profound philosophic thoughts including in the field of ethics, Seneca gave an example of Epicure who blamed death-hungries: "It is absurd to strive for death being satiated with life".

Nevertheless, there were adherents to voluntary life termination in the past. Among them was Friedrich Nietzsche: "A sick man is a parasite of society. It is inappropriate to continue to live in a certain state. A miserable life in a cowardly dependence from physicians and artificial measures must arouse a profound contempt of society. Doctors should be mediators in this contempt; they shouldn't give prescriptions but a new dose of aversion for their patients every day. The highest interest of life requires a merciless suppression and elimination of a degenerating life" (Nietzsche, 1990). In addition to the "list" of acute bioethical current problems the reproductive priorities of "golden billion" of the population living in rather small group of highly developed countries with sustained political system and up-to-date information technology should be assigned. The calls for the limitation of the increase in the birth rate by any means, as well as through the latest achievements in pharmacy and vaccination or surgical intervention, are heard with respect to the rest 5 billions of people from the countries generally with preindustrial stage of development. To what extent such researches and their realization are correct from moral point of view remains to be an acute ethical issue.

Over the last years another negative factor became widely spreading practice of conducting biomedical and other experiments and tests in the "southern" countries that are much cheaper here than in the developed countries. This kind of problems passes from bioethical to the status of political ones and become possible "thanks to" not only a legal but usual illiteracy of the subjects under test. The production of modified products, genetic construction in the field of bios, irreplaceable use of natural resources, nanotechnologies and other modern manifestations of runaway scientific and technological progress undoubtedly have their own scientific and practical values. At the same time, they carry vital discrepancies of a moral character not only with respect to presently living human beings but also to the generations to come. The main discrepancy is between increasing technocratic power of a human being and basic humanistic principle that "a human being is of the highest value". The evaluation of moral significance of actions and practice in the sphere of living thing, as well as the formation of legal levers for the leveling of any factors that cause damage to human being are the main tasks of governments and societies and these make a true sense of humanism. "Do not harm" medical principle (premium non nocere) is relevant and demanded practically in all the spheres of the use of the latest technologies and technical rearmament.

The German philosopher Immanuel Kant declared an ethical principle that says: "Act in accordance to such maxim guided by which you may wish this to be general law" (Narski, 1976). As far back as in XVIII century when the ethical problems of attitude of a man to his health, social being and entourage seemed to be not too evident there were postulates formulated that are topical and demanded nowadays.

\section{The Legal Support of the Solution of Bioethical Issues}

Today to a large extent thanks to bioethics there is a clear understanding on the part of governments and societies of the necessity of the elaboration of national policies and legal events, the establishment of the systems of legal protection of human beings from unauthorized intervention of progressive technologies and technics into human life and health. According to the Universal Declaration on Bioethics and Human Rights adopted by UNESCO General Conference in October 19, 2005, its main purpose is "to ensure universal complex of principles and procedures to be guided by the governments while elaborating their legislative norms, policy or other instruments in the field of bioethics".

The formation of a legal space in the field of bioethics can be represented in the form of a "triangular" model with the orientation toward three focuses. Each of them represents global complex of measures, initiatives and actions on the formation of:

1) Institutional environment (policy including national standards, legislative framework, healthcare reforms and reforms in other sectors connected with human life, the strengthening of partner relations with civil society, etc.)

2) Educational policy (elaboration of new study programs, training courses, disciplines, workbooks, special literature; training of scientific brainpower, masters) 
3) Ethical committees (structures for ensuring the adoption of legal decisions conforming to moral values) (Galandarli, 2012)

It is obvious that such a model can constitute a basis of scientific researches and applied bioethics. The conflicts of "values" and "rights" affecting vital interests of a human being require its legal settlement on a new organized level. The protection of human rights can be ensured owing to the forming legal institutionalization of bioethics. The introduction of an ethical component to the systems of state control after biomedical scientific researches and medical practice gives a unique resource for a balanced development of life science in accordance with moral needs of society. The creation of ethical structures is a next stage after providing in the constitution of the right to health and after the development of a national program or conception. It is ethical committees that become a basis of legal system in bioethics. Being a new social institution, ethical committees should elaborate moral rules of the functioning of the scientific, research and medical institutions, provide an ethical expertise and recommendations on complicated situations requiring social, philosophic and moral settlement in full conformity to universal values. This can be structures of various compositions and status; they can be analytical and consultative or controlling. They are not similar in different countries by force of distinctions of their existing legislations, organization of national healthcare services, economic conditions, social, cultural and moral values. International organizations have developed a number of normative legal documents that recommend some general principles of policy in the sphere of protection of human rights to life and health and that can be duly adapted to the conditions of each single country.

Ethical committees can exist only in democratic societies. Even if a state has a higher technological level of development, the absence of pluralism doesn't make it possible to realize a moral in making one or another decision in a conflict situation.

\subsection{Azerbaijan Has Been Working on Legal Support of Bioethical Matters}

Since 1992 the Republic of Azerbaijan has carried out works on legal support of bioethical principles. A number of important normative acts aimed at the protection of human rights in the sphere of healthcare are adopted; among them there is Laws on Protection of Health of Population, on Pharmaceutical Activity, on Sanitary-Hygienic Welfare of Population, on Narcological Service, etc. The most important of them is a legal act adopted in 1997; it is the Law on Protection of Health of Population of the Republic of Azerbaijan. In Chapters III and IV of the Law there is a list of all rights that are vested in the citizens and other persons of the republic in the sphere of healthcare and medicine. Particularly, Article 25 says that "every citizen has a right to get an available information on the state of his health in an accessible form, including information on the results of examination, occurrence of disease, its diagnosis and prognosis, methods of treatment, risks related with them, possible options of medical interference, their consequences and results of the treatment provided" (http://natella-klinika/ucoz/index/0-6)

The components of state policy on the normative legal regulation and settlement of problems of bioethics include (1) the creation of institutional environment, (2) measures on ensuring human (patient's) rights, (3) measures on providing education. To realize this policy it is necessary:

1) Adoption of laws and subordinate legislation determining rights and obligations of patients, representatives of medical profession, healthcare institutions;

2) Adoption of periodically revised medical and other professional codes, other similar documents developed on the basis of agreement and mutual understanding between the representatives of citizens, medical community, scientific researchers, patients, politicians, and public leaders;

3) Development of cooperation between patients and medical workers, pharmacists and medical services producers on the basis of compromises under the conditions of intersection of corporate interests;

4) Providing state support to the establishment and successful work of non-governmental social organizations carrying out their activities in the sphere of bioethics;

5) National-scale organization of conferences, public meetings with the participation of all parties concerned in order to facilitate the development of mutual understanding, formation of positive public opinion;

6) Involvement of mass media in order to inform and support the awareness of population with respect to the patients' rights, stimulation of the parties to a constructive dialogue;

7) Enlightenment and legal activity in the sphere of protection of human rights to safety of life, health and dignity.

The education and improvement of the awareness regarding the issues of bioethics are one of the main tasks of 
international organizations that develop basic documents for the use by the states in their enlightenment activity in civil society. Particularly, UNESCO prepared an academic Program on bioethics designated for "specialists, scientists, lawyers, journalists, representatives of authorities, a wide audience and other target groups (Bioethics: documents, terms, 2009). UNESCO departments of bioethics established in the regions facilitate the expansion of cooperation. Such department is established and operating in Azerbaijan. The XVIII session of UNESCO International Committee of Bioethics organized with the support of Heydar Aliyev Fund, National Academy of Sciences, UNESCO National Commission of the Republic of Azerbaijan under the auspices of the Government of Azerbaijan was held in summer of 2011. It considered and discussed the problems of development of legal trend of bioethics, creation of national legislative framework in the sphere of bioethics and that of human rights. (Huseynova, Mammadov, Mustafayeva, Ahmadov \& Aliyeva, 2012) The fact that hold such prestigious meeting in Azerbaijan once more underline its status of democratic secular civil state devoted to universal values.

\section{Conclusion}

On the basis of the carried investigation we come to the conclusion that the creation of institutional environment supposes integrity and unity of work of all elements of the system of legal support of biomedicine, scientific researches and technical rearmament, creation of mechanisms of state and other control, development of legal culture of population determining the importance of expertise and development of inter-corporate control mechanisms of professional ethics. It is necessary to take into account national features and a cultural ethical variety in law-making processes in bioethics. For example, the preamble of the Universal Declaration on Bioethics and Human Rights says that "all human beings, without distinction, should benefit from the same high ethical standards in medicine and life science research". Though health of a human being remains to be an important value in any society, however each country has its own ethical standards - the moment of death is fixed differently (in the context of transplantation); the personalized status of human embryo is evaluated (in the context of artificial abortion and other aspects of reproductive technologies); theological world views of nations are different, etc.

The list of rights and freedoms specified in international agreements is not unconditional and comprehensive for each state. National legislations provide additional rights to their citizens that are defined by the nature and structure of social system, level of economic development, historical traditions, and moral specifics. The cultural variety of different nations being a source of exchange of innovations and creativity represents general heritage of mankind, but it cannot be used against national features. The legislative framework in bioethics must expand not only in healthcare in order to solve purely medical problems. It needs a great range of legal acts that harmonically and fully protect human right in complicated spectrum of human life. It is important that galloping medical, biological and other technologies do not cause damage but bring benefits to human being. In the name of protection of worthy lives existing people and next generations, the main obligation of mankind is to observe universal values in all their occurrences of scientific and technological progress. The analysis shows that bioethics gives a chance of consolidation of sound forces in society. The level of observance of bioethical standards is a demonstrative feature of all democratic societies.

\section{References}

Aliyeva, M. (2005). Euthanasia as a moral- legal problems. Bulletin of Baku state university, No.1.

Galandarli, N. (2012). Problems of bioethics in the light of Azerbaijan legislation. Materials of XVI Republican scientific conference of doctorates and young scientists. Baku.

Gay-Williams, J. (1989). The Wrongfulness of Euthanasia. Euthanasia: the moral issues. New York.

Huseynova, I., Mammadov, V., Mustafayeva, A., Ahmadov, I., \& Aliyeva, F. (2012, September 2-5). Bioethics education in Azerbaijan: content, methods, trends and perspectives. Materials of the UNO 8-th International Conference «Bioethical education: content, methods, directions». Israel.

Kant, I. (1984). Critique of practical reason. Moscow.

Mustafayeva, A. (2009). Bioethics: documents, terms. Baku.

Narski, I. (1976). Immanuel Kant. Moscow.

Nietzsche, F. (1990). Twilight of the idols or, How to Philosophize with a Hammer (Vol. 2). Moscow.

Hang-Martin, S. (1988). Bioethik in den. USA.

Seneca, L. (1977). Moral letters to Lucilius. Moscow.

Siluyanova, I. (2001). Bioethics in Russia: values and laws. Moscow. 
Tishenko, P. (2009). Bioethics: "Multiplicity and thought". Philosophy and ethics.

UNESCO. (2005). Universal declaration on Bioethics and Human rights. Retrieved from http://www.un/org/documents/decl_conv/conventions

Yudin, B. (1994). Bioethics, medical ethics, theory of values. Moral values and personality. Moscow.

\section{Copyrights}

Copyright for this article is retained by the author(s), with first publication rights granted to the journal.

This is an open-access article distributed under the terms and conditions of the Creative Commons Attribution license (http://creativecommons.org/licenses/by/3.0/). 